\title{
Injury consequences from participation in professional rugby league: a preliminary investigation
}

\author{
Rudi A Meir, Kevin N McDonald, Ray Russell
}

\begin{abstract}
Objective-To conduct a preliminary investigation to determine if injuries sustained while playing professional rugby league have long term consequences for players after retirement from their playing careers.

Method-Twenty eight retired players, who had competed in the professional Australian Rugby League competition, responded to a 23 item survey. Respondents were asked to recall all injuries that resulted in them being unable to play for five or more consecutive games. The survey asked players to provide information about age, playing weight, number of games played, position played, number and type of major injuries sustained during their career, and the effects of these injuries both during their career and after retirement.
\end{abstract}

Results-Within the limitations of this study's small sample, it is suggested that players with long term consequences of injury may experience a variety of detrimental effects into retirement, including job limitations, reduced income earning potential, and increased personal medical costs.

Conclusion-Although research relating to the type and severity of injuries sustained while playing rugby league has been previously undertaken, investigation into the effect injuries sustained during a professional career have on players after retirement has been neglected. This preliminary investigation suggests that retired professional rugby league players may have at least one long term consequence of injuries sustained during their playing career.

(Br f Sports Med 1997;31:132-134)

Faculty of Health Sciences, The Centre for Exercise Science and Sport

Management,

Southern Cross

University, PO Box

157, Lismore, NSW, 2480, Australia

R A Meir

K N McDonald

R Russell

Correspondence to: Mr Meir.

Accepted for publication 8 January 1997
Keywords: rugby league; injuries; retirement

For professional rugby league in Australia, the length of the competition, the intense nature of the game, and changes to the rules have all contributed to increased demands on players. This has raised questions about the frequency and type of injuries sustained by players and the steps that need to be taken to guard against injury. ${ }^{12}$ It seems reasonable to assume that the type and seriousness of an injury may affect the long term vocational opportunities afforded retired players. Further, it may be that the more serious the injury, the greater the potential for continuing problems.

The (Australian) Rugby League Players' Union (RLPU) has raised the issue of workers compensation for its members on the basis that many players are now full time professionals and therefore should be entitled to the same coverage as other employees. ${ }^{3}$ This preliminary investigation was undertaken to determine if in fact retired players do experience long term effects due to injury sustained during their careers.

\section{Method}

DEFINITIONS

Elite level players-players graded into the New South Wales Rugby League (NSWRL) competition.

Major injury -injury requiring a player to miss five $^{1}$ or more consecutive matches.

Retirement-no longer actively participating as a player in the NSWRL competition.

Occupational prospects - possible job opportunities (consistent with their level of training or experience, or both) after retirement from professional rugby league.

SUBJECTS

Subjects were retired professional rugby league players.

\section{SURVEY DESIGN}

The survey comprised 23 separate items that considered the following broad areas:

(a) Player demographics (for example, age, playing weight, etc)

(b) Number of games played and length of professional career

(c) Playing position during professional career (d) Representative honours attained and number of games

(e) Number and type of major injuries sustained during professional career

(f) Immediate effects of an injury (for example, games missed)

(g) Long term effects of an injury (for example, loss of income, physical disability).

\section{PROCEDURE}

A draft survey was developed and distributed to relevant qualified professionals (for example, qualified sports physicians and practising sports physiotherapists) and the RLPU, for input into question structure, sequence, and relevance. A copy of this survey was then completed by a group of retired professional players 
Table 1 Mean age (years), height* $(\mathrm{cm})$, and weight* $(\mathrm{kg})$ of 28 respondents at the various stages of their playing careers

\begin{tabular}{lcll} 
Stage of career & Mean (SD) age & Mean (SD) height & Mean (SD) weight \\
\hline $\begin{array}{l}\text { Junior/school boy } \\
\begin{array}{l}\text { Start of professional rugby league } \\
\text { career }\end{array}\end{array}$ & $9.9(2.9)$ & N/A & N/A \\
At retirement & $19.8(2.6)$ & $179.7(8.2)$ & $79.7(11.8)$ \\
& $30.5(3.1)$ & $179.7(8.2)$ & $85.3(11.7) \dagger$
\end{tabular}

^ Respondents were only asked to provide details of weight and height at the start of their professional careers and upon retirement.

$\dagger$ Represents a significant $(P<0.0001)$ increase in body weight

Table 2 Mean (SD) number of games played by each of 28 players during their professional career

\begin{tabular}{llcc}
\hline $\begin{array}{l}\text { Level of } \\
\text { participation }\end{array}$ & $\begin{array}{l}\text { Frequency of } \\
\text { response }\end{array}$ & $\begin{array}{l}\text { Total number of games } \\
\text { played }\end{array}$ & $\begin{array}{l}\text { Mean }(S D) \text { number of games } \\
\text { played }\end{array}$ \\
\hline U/21 or U/23 & 17 & 338 & $19.8(13.9)$ \\
Reserve grade & 28 & 817 & $29.1(25.2)$ \\
First grade & 27 & 2958 & $109.5(87.4)$ \\
City or country & 15 & 52 & $3.5(2.3)$ \\
State & 11 & 84 & $7.6(7.4)$ \\
International & 10 & 148 & $14.8(4.13)$ \\
\hline
\end{tabular}

to determine its face validity. The final survey design and content was approved by the ethics committee.

The survey had a limited distribution to 47 retired ex-professional players. Thirty copies were distributed by the RLPU and a further 17 copies were distributed by the authors. Each subject received a package containing (a) a covering letter explaining the primary purpose of the survey; (b) one copy of the survey; and (c) a reply paid envelope in which to return the completed survey. At no time was the issue of compensation raised in any correspondence. Each survey was coded for administrative purposes only and kept separate from the recipient's name and address. Respondents were advised that their details would remain completely anonymous. Returned surveys were analysed and data aggregated for descriptive presentation of responses.

\section{Results}

Twenty eight retired players completed the survey (representing a $60 \%$ return rate). The mean age (SD) of respondents was 45.4 (8.3) and the mean age of retirement from the game was 30.5 (3.1). The mean entry age of players as participants into competitive rugby league was 9.9 (2.9), with a mean age of entry into professional competition of 19.8 (2.6) (table $1)$. Table 1 also provides details of the mean height and weight of respondents at the start of their professional career and upon retirement. Body weight was significantly increased $P<0.0001)$ between their entry into professional competition and retirement. Seventeen $(61 \%)$ respondents played as backs for the major part of their career with the remainder playing in the forwards. Table 2 presents the mean number of games played by all respondents at the various levels of professional competition. Fifteen respondents had played at some representative level during their professional careers. Further, eight $(29 \%)$ of the respondents had played one or more other forms of "football" (that is, Australian Rules, Rugby Union, and soccer) at a competitive
Table 3 Conditions resulting from major injuries (established by medical examination) in 23 respondents

\begin{tabular}{lc}
\hline Condition & Frequency \\
\hline Joint replacement & 1 \\
Arthritis & 15 \\
Chronic back pain & 9 \\
Restricted joint mobility (joint stiffness) & 12 \\
Problems with hearing & 1 \\
Chronic headaches & 2 \\
Joint reconstruction & 3 \\
Dental problems & 4 \\
Chronically stiff fingers & 5 \\
\hline
\end{tabular}

^ For example, related to cauliflower ears.

level before starting their professional rugby league career.

Seventeen $(61 \%)$ respondents had had three major injuries or fewer during their professional career; eight $(28 \%)$ had had between four and seven major injuries, and three $(11 \%)$ more than eight major injuries. For $23(82 \%)$ respondents medical examination had established that a variety of conditions experienced since retirement were a direct consequence of injury sustained during their professional playing career (table 3). However, this group also indicated that the effects of these injuries might have been compounded by injury sustained in the following areas: work $(n=4)$, other football sports $(n=13)$, accidents $(n=2)$, and other ( = 3)-for example, complications after surgery (table 4).

A combination of age and injury were the most common $(11(39 \%))$ reasons for retirement from professional rugby league, followed by injury in seven $(25 \%)$, age in six $(21 \%)$, and other factors (for example, lack of interest in competing, etc) in four (14\%). Further, eight $(29 \%)$ respondents indicated that injury had resulted in their early retirement from professional rugby league.

Five $(18 \%)$ respondents had had no long term consequences of injuries sustained while playing professional rugby league. Of these, four had been retired for fewer than six years. Twenty $(71 \%)$ respondents indicated that, in their opinion, they had continued to be able to generate income, while $24(86 \%)$ had not experienced any occupational limitations as a result of injury sustained during their professional career. However, six $(21 \%)$ were of the opinion that their injury had affected their ability to generate income and four $(14 \%)$ thought that injury had affected their ability to work in their chosen profession (table 5).

\section{Discussion}

Owing to the clear limitations of the sample size, interpretation of these results should be viewed with some caution. However, results from this preliminary study indicate that most respondents had some form of long term consequence of major injuries received during their professional career. These included arthritis, chronic back pain, restricted joint mobility, and chronically stiff fingers (table 3). Previous research has reported that $50 \%$ of rugby league players will have some type of injury during a season, ${ }^{14}$ with about a quarter of these being major injuries. 
Table 4 Other injuries in 23 respondents that might have compounded the long term consequences of injuries sustained while playing professional rugby league

\begin{tabular}{lcc}
\hline Area & Frequency of response & No (\%) of respondents \\
\hline Work & 4 & $4(17)$ \\
Other sports & 13 & $13(57)$ \\
Accidents & 2 & $2(9)$ \\
Other & 3 & $3(13)$ \\
\hline
\end{tabular}

Table 5 Reported consequences of injury as a result of participation in professional rugby league for 28 retired players

\begin{tabular}{llllc}
\hline $\begin{array}{l}\text { Response } \\
\text { category }\end{array}$ & $\begin{array}{l}\text { fob } \\
\text { limitations } \\
\text { No(\%) }\end{array}$ & $\begin{array}{l}\text { Early } \\
\text { retirement } \\
\text { No(\%) }\end{array}$ & $\begin{array}{l}\text { Medical } \\
\text { costs } \\
\text { No (\%) }\end{array}$ & $\begin{array}{l}\text { Loss of } \\
\text { income } \\
\text { No (\%) }\end{array}$ \\
\hline No & $24(86)$ & $16(57)$ & $19(68)$ & $20(71)$ \\
Unsure & $0(0)$ & $4(14)$ & $3(11)$ & $2(7)$ \\
Yes & $4(14)$ & $8(29)$ & $6(21)$ & $6(21)$ \\
\hline
\end{tabular}

It is reasonable to assume that the debilitating consequences of major injuries will worsen without appropriate medical care, and with the number of years after retirement. This may explain why four of the five respondents who had been retired for fewer than six years did not report any long term consequences of injury. However, complications may develop later in life.

Joint injuries are thought to produce longlasting side effects, such as increased risk of osteoarthritis, restricted joint movement, and the possibility of joint replacement or reconstruction..$^{5-7}$ Osteoarthritis results in pain that can inhibit quality of life and, possibly, career options, while severe pain may lead to sufferers seeking joint replacement surgery. At present, vigorous physical activity cannot be pursued after such surgery, ${ }^{5}$ possibly limiting vocational options after this procedure.

Other factors that may affect the development of long term consequences of major injuries are the total number of games played or level of competition, or both. Further investigation may determine that players with relatively fewer games played at a lower level of competition do not experience the same frequency or severity of injury as those players with a more extensive playing history.

The position played also needs to be considered. Previous research ${ }^{289}$ suggests that forwards are more susceptible to injury than backs. The ratio of forwards to backs in this study was $2: 3$, but of the five respondents with no long term consequences, only one was a forward. Thus the backs may have had fewer injuries than the forwards, possibly decreasing the likelihood of long term consequences developing. Further research is needed to determine whether the position played has an influence on the areas of the body affected by injuries. Injury to different body areas may lead to different long term consequences and differ- ences in their severity. Respondents were only asked to recall injuries received during their professional career. Possibly, some debilitating effects might have been compounded by other factors (table 4).

Of the respondents with long term complications, eight (29\%) had lost income during their career owing to injury. This is not surprising given the relatively high number $(25 / 28(89 \%))$ of respondents who had worked during their playing careers. Injuries forced eight (29\%) respondents to retire prematurely, while another four (14\%) were not sure if injury had resulted in their early retirement. As a result, early retirement due to injury seems to be the single biggest factor contributing to (potential) loss of income.

Six $(22 \%)$ respondents thought their ability to generate income or work in their chosen occupation had been reduced because of the consequences of old injuries. For three respondents this had occurred since retirement owing to the effects of these injuries.

The ability to pursue relevant vocational prospects plays a vital part in long term financial security. The issue of continuing medical costs incurred as a result of injury during a player's career must also be considered. Six respondents reported that they had to cover their own medical costs associated with these long term injury complications.

\section{Conclusion}

Although limited by a relatively small sample, this preliminary study suggests that retired professional players may have at least one long term consequence of injuries received while playing professional rugby league. Such injuries may reduce income earning potential and employment options, and lead to increased personal medical costs. These results may support the need for some form of appropriate protection (for example, workers' compensation) for retired professional players.

1 Gibbs N. Injuries in professional rugby league: a three-year prospective study of the South Sydney professional rugby eague football club. Am f Sports Med 1993;21:696-700.

2 Seward H. Football injuries in Australia. Search 1990;21: 197-200.

3 Russell M, Tom E. ALP puts plan for football compo. The Sydney Morning Herald, 1994 June 14:3.

Smithers M, Myers P. Injuries in sport: a prospective casualty study. Med $¥$ Aust $1985 ; 142: 457-61$.

alty study. Med f Aust 1985;142:457-61. 343-57.

6 Neyret P, Donell ST, Dejour D, Dejour H. Partial meniscectomy and anterior cruciate ligament rupture in soccer players: a study with a minimum 20 -year follow up. Am $\mathcal{F}$ Sports Med 1993;21:455-60.

7 Seward H, Orchard J, Hazar, H, Collinson D. Football injuries in Australia at the elite level. Med $\mathcal{F}$ Aust 1993;159:298301

8 Havkins SB. Head, neck, face, and shoulder injuries in female and male rugby players. The Physician and Sports Medicine 1986;14:111-18.

9 Sparks JP. Rugby football injuries, 1980-1983. Br $\mathcal{F}$ Sports Med 1985;19:71-5. 